\title{
Design and Construction of a Mini Hydro Turbine Model
}

\author{
Emmanuel Ighodalo Okhueleigbe*, Okene David Ese \\ Email address: \\ okhueleigbe.emmanuel@fupre.edu.ng (E. I. Okhueleigbe), okene.david@fupre.edu.ng (O. D. Ese) \\ ${ }^{*}$ Corresponding author
}

Department of Electrical/Electronic Engineering, College of Technology, Federal University of Petroleum Resources Effurun, Warri, Nigeria

\section{To cite this article:}

Emmanuel Ighodalo Okhueleigbe, Okene David Ese. Design and Construction of a Mini Hydro Turbine Model. American Journal of Modern Energy. Vol. 4, No. 1, 2018, pp. 1-6. doi: 10.11648/j.ajme.20180401.11

Received: October 15, 2017; Accepted: October 31, 2017; Published: January 8, 2018

\begin{abstract}
This research is aimed at design and construction of a mini hydro turbine generator that can be made available at the consumer level, so as to improve the generation and availability of power at lower rate without pollution to the environment so as to help boost power generation, quality of power to its power consumers in developing countries. Pelton's wheel design was used for the turbine research. Water stored in a tank or reservoir at a three meter height contains potential energy, this water is allowed to fall on the turbine wheel which drives the turbine. The potential and kinetic energy available in the water is converted to mechanical energy by rotating the runner connected to the turbine blade. The runner is connected to the rotor part of the alternator (containing the permanent magnet) and the stator (containing the windings) which is kept at permissible air gap to the rotor for effective induction. The voltage is tapped out from the stator as a single phase output, which is used to power household utilities and other machineries which need power supply. The result obtained was gotten from the various tests carried out on this research the tests includes water flow rate test, stator coil resistance test, output voltage test, power quality test and rotational speed test. The output power result shows that domestic power could be generated at individual residential level this will help improve and stabilize the power in the national grid.
\end{abstract}

Keywords: Energy, Power, Generation, Water, Turbine

\section{Introduction}

The Utilization of gas power plant for energy (power) generation all over the globe has become a global challenge as the world is drifting from generating system and facilities that pollute the environment to that which is environmentally friendly, hence hydro schemes should be encouraged in line with renewable sources of power generation so as to drive the power sector to its power stabilization stage for developing countries. Hydro power could describe as a renewable form of energy, hydro power plant derives its power from water falling from higher to a lower level, and extracted by means of waterwheels or hydraulic turbines [1] [2]. Hydropower has among the best conversion efficiencies of all known energy sources (about 90\% efficiency, water to wire). It requires relatively high initial investment, but has a long lifespan with very low operation and maintenance costs [3] [4] [5]. The initial cost could be reduced to minimum with the application of mini hydro turbine (including local fabricated components), with little or no running cost for small scale power consumers. Hydro power generation and national grid efficiency could be improved by incorporating mini hydro generator at the consumer level.

Design overview: Hydropower turbine converts the hydraulic (potential and kinetic) energy of the descending water to mechanical energy by using a hydraulic turbine. The hydro-turbines are in turn connected to the generator that converts the mechanical energy to electrical energy [6] [7]. This is applicable to conventional means of hydro power generation in a very much larger scale. Figure 1 shown below depicts the operational processes.

The dam stores water at a height that is been design for the water head to produce the required pressure. The penstock conveys the pressurized water from the dam to the turbine.

The turbine is rotated by pressure of the water on the blade and the turbine is connected to the generator to produce electricity. 


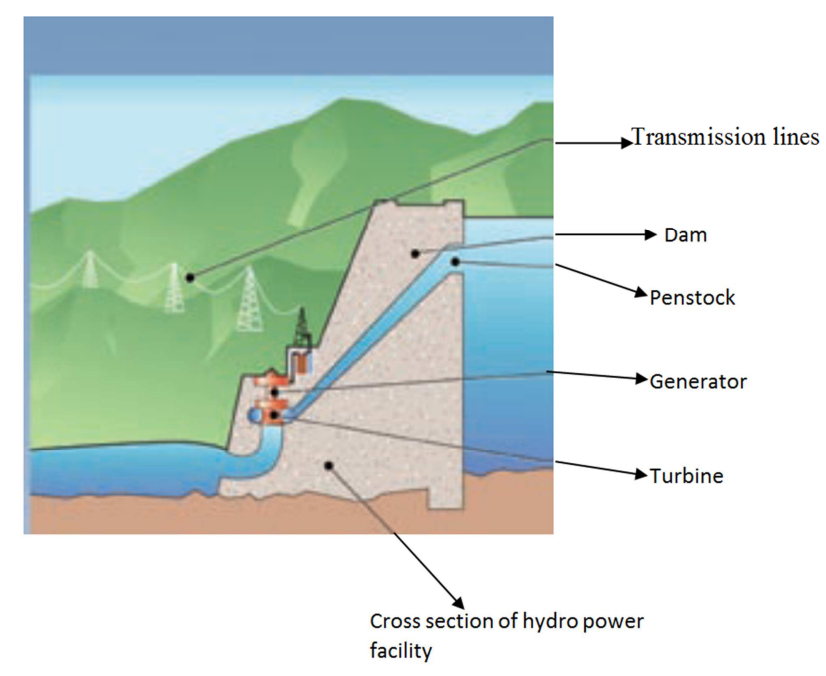

Source: Energy Efficiency and Renewable Energy (2003) [8].

Figure 1. Typical Hydro Turbine Generation Scheme.

\section{Methods}

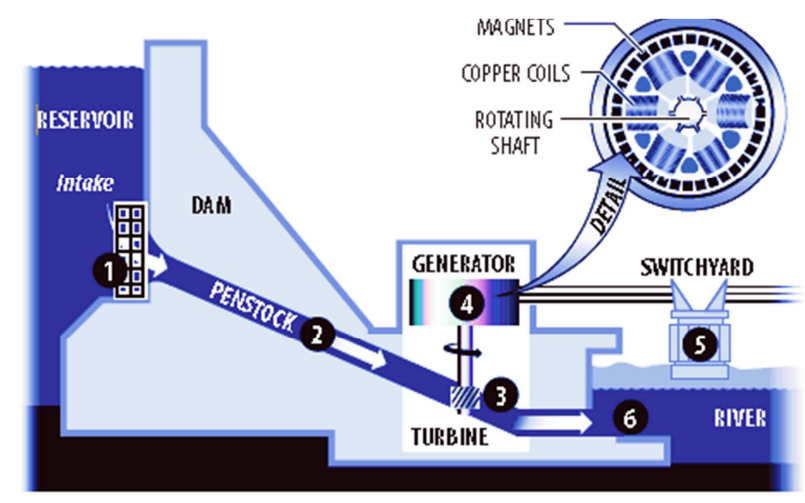

Source: Hydropower “The Need Project" 2015 [9]

Figure 2. Typical Hydro-Turbine Power Plant.

The arrows signify the direction of water flow, that is from the reservoir through the penstock to the turbine and back to the reservoir.

In the course of this research, it was observed that hydroturbine power plants can be classified based on the overall output power generated and they are listed below;

1. Large Hydropower

Department of Energy (DOE) defines large hydropower as facilities that have a capacity $>30 \mathrm{MW}$.

2. Small Hydropower

Department of Energy (DOE) also defines small hydropower as facilities that have a capacity of $100 \mathrm{~kW}-30 \mathrm{MW}$.

3. Micro Hydropower

A micro hydropower plant has a capacity of up to $100 \mathrm{~kW}$. A small or micro-hydroelectric power system can produce enough electricity for a home, farm, or village. e.t.c

\subsection{Reservoir}

The water reservoir can be described as a place where water is stored. This can be a naturally-flowing river (run-of river) or a dam. The water in the reservoir is usually located on a higher level as compared to the rest of the constructed structure. The height of water level in the reservoir decides how much potential energy the water possesses and the higher the water level, the more its potential energy.

The height of water in the reservoir is usually higher than the natural height of water flowing in the river, so it is considered to have an altered equilibrium. This also helps to increase the overall potential energy of water, which in turn, helps ultimately to produce more electricity in the power generation unit.

\subsection{Intake}

These are the gates built on the inside of the dam. The water from reservoir is released and controlled through these gates. These are called inlet gates because water enters the power generation unit through these gates. When the control gates are opened the water flows due to gravity through the penstock and towards the turbines. The water flowing through the gates possesses potential and kinetic energy.

\subsection{Penstock}

The penstock is a passage that conveys the water flowing from the reservoir to the power generation unit (which is made up of turbines, generators and control/monitoring devices). The water in the penstock possesses kinetic energy due to its motion and potential energy due to its height. The amount of water flowing through the penstock is usually controlled by a valve (control gate).

\subsection{Turbine}

Water flowing from the penstock is allowed to enter the turbine-part of the power generation unit, which houses the turbine and the generator. When water falls on the blades of the turbine, the hydraulic energy (kinetic and potential energy) of water is converted into mechanical energy (through rotational motion) of the blades of the turbine. The rotating blades cause the shaft of the turbine (which has coupled to it, the generator) to also rotate.

The general formula for the determination of hydraulic power is given as

$$
P_{h}=\rho * \mathrm{~g} * \mathrm{Q} * \mathrm{H}
$$

The mechanical power available at the output of the turbine could be determined with the relationship

$$
\mathrm{P}_{\mathrm{m}}=\mathrm{\eta} * \mathrm{P}_{\mathrm{h}}
$$

$p_{h}$ is the power produced by the falling water

$P_{m}$ is the mechanical power produced at the turbine shaft (Watts)

$\rho$ is the density of water $(1000 \mathrm{~kg} / \mathrm{m} 3)$

$\mathrm{g}$ is the acceleration due to gravity $\left(9.81 \mathrm{~m} / \mathrm{s}^{2}\right)$

$\mathrm{Q}$ is the water flow rate passing through the turbine $\left(\mathrm{m}^{3} / \mathrm{s}\right)$

$\mathrm{H}$ is the effective pressure head of water across the turbine (m) 
$\eta$ is the efficiency of the turbine.

The turbine efficiency is defined as the ratio of power supplied by the turbine (mechanical power transmitted by the turbine shaft) to the absorbed power (hydraulic power equivalent to the measured discharge under the net head).

Designed Hydro Power $\left(P_{h}\right)$

$$
P_{h}=\rho * \mathrm{~g} * \mathrm{Q} * \mathrm{H}
$$

With water head of 3 meters and flow rate of 1 litre per second $(1 / \mathrm{s})$,

$$
\begin{gathered}
\mathrm{P}_{\mathrm{h}}=1000 * 9.81 * 0.001 * 3 \\
P_{h}=29.43 \text { watt }
\end{gathered}
$$

Ideally, hydraulic power at the turbine level is 29.43 watt

Mechanical output Power $\left(\mathrm{P}_{\mathrm{m}}\right)$

$$
\mathrm{P}_{\mathrm{m}}=\eta * \mathrm{P}_{\mathrm{h}}
$$

Assuming turbine efficiency $(\mathrm{y})$ is $70 \%$

$$
\begin{gathered}
P_{\mathrm{m}}=0.7 * 29.43 \\
P_{\mathrm{m}}=20.6 \mathrm{watt}
\end{gathered}
$$

Ideally, mechanical power at shaft is 20.6 watt.

\subsection{Generator}

Technically, in this case the generator could be refers to as an alternator which is made up of a rotor and a stator. Electricity is produced through faradays law of electromagnetic induction, which states that when a conductor is moved across a magnetic field so as to cut through the lines of flux created by a magnetic material, an electromotive force (EMF) is produced in the conductor.

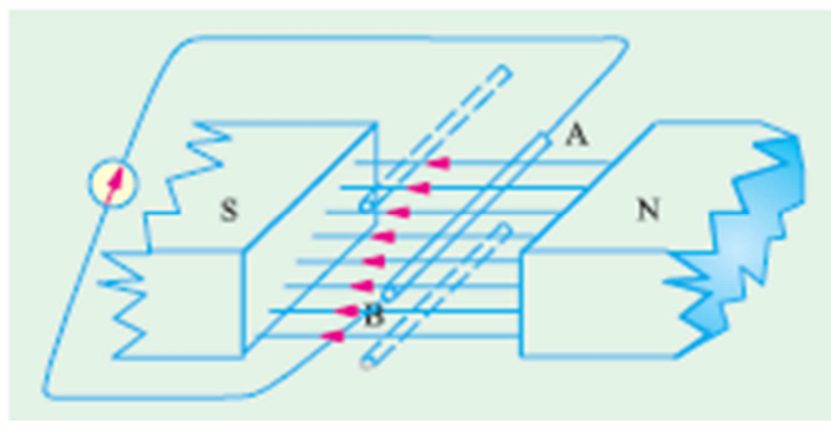

Source: Electrical Technology (Vol 1). [10]

Figure 3. Illustration of Electromagnetic Induction.

The rotor basically is made up of conducting coils while the stator is of magnetic materials (either permanent or electromagnets).

The runner of the turbine rotates the rotor-shaft inside the generator which cuts through the magnetic field created by the stator magnets, and that is converted into electricity by electromagnetic induction.

The total number of turns the coil windings should have is dependent on the expected output voltage, the frequency of generation, rotor speed, magnetizing strength of the magnets and the cross-sectional area of the magnets. The relationship is represented mathematically as;

$$
\mathrm{N}=\mathrm{E} /\left(\mathrm{B} * \mathrm{~A}_{\mathrm{T}} * \mathrm{w} * \sin w \mathrm{t}\right)
$$

Design output voltage

$$
\mathrm{E}=\mathrm{B} * \mathrm{~A} * \mathrm{~W} * \mathrm{~N}
$$

At flux density $(\mathrm{B})=1.4 \mathrm{~T}$,

$$
\text { Area }(\mathbf{A})=2 * 10^{-4} \mathrm{~m}^{2},
$$

w equals to 10 revolution per seconds,'

Total no of turns $(\mathrm{N})$ equals 2370

$$
\begin{gathered}
\mathrm{E}=1.4 * 2 * 10^{-4} * 10 * 2370 \\
\mathrm{E}=6.65 \text { volts } .
\end{gathered}
$$

$\mathrm{N}$ is Total number of coil turns

E is Generated output voltage (in Volts)

$B$ is Magnetic flux density (in Tesla)

$\mathrm{A}_{\mathrm{T}}$ is Total cross-sectional area of the magnets $=\mathrm{A}^{*} \mathrm{n}$ (in $\left.\mathrm{m}^{2}\right)$

$\mathrm{n}$ is total number of rotor magnet

$\mathrm{W}$ is angular velocity $=2 * \mathrm{pi} * \mathrm{f}$ (in radians/second)

$F$ is frequency of generation: usually between $50-60 \mathrm{~Hz}$ (in Hertz)

$t$ is instantaneous time

Determination of the frequency of generation is dependent on the rotational speed of the rotor and it is related by:

$$
\mathrm{N}_{\mathrm{s}}=120 \mathrm{f} / \mathrm{p}
$$

$\mathrm{N}_{\mathrm{s}}$ is Rotational speed of rotor as determined by a tachometer (in revolution/second)

$f$ is frequency of generation (in Hertz)

$p$ is number of poles

Designed rotational speed

Desired frequency (f) of $50 \mathrm{~Hz}$,

No of poles (p) equals to 10

$\mathrm{N}_{\mathrm{s}}=120 \mathrm{f} / \mathrm{p}$

$$
\mathrm{Ns}=\frac{120 * 50}{10}
$$

$\mathrm{N}_{\mathrm{S}}=600 \mathrm{rpm}$.

Therefore, the root mean square value of the generated voltage is given by

$$
\mathrm{V}_{\mathrm{rms}}=0.707 * \mathrm{E}(\text { Volts })
$$

The power rating of the generator is majorly dependent on the current-carrying capacity of the conducting coils. The power output is given as;

$$
\mathrm{P}=\mathrm{V} * \mathrm{I} \text { (Watts) }
$$

$\mathrm{V}$ is Voltage (Volts)

I is Current (Amperes) 


\subsection{Choice of Design}

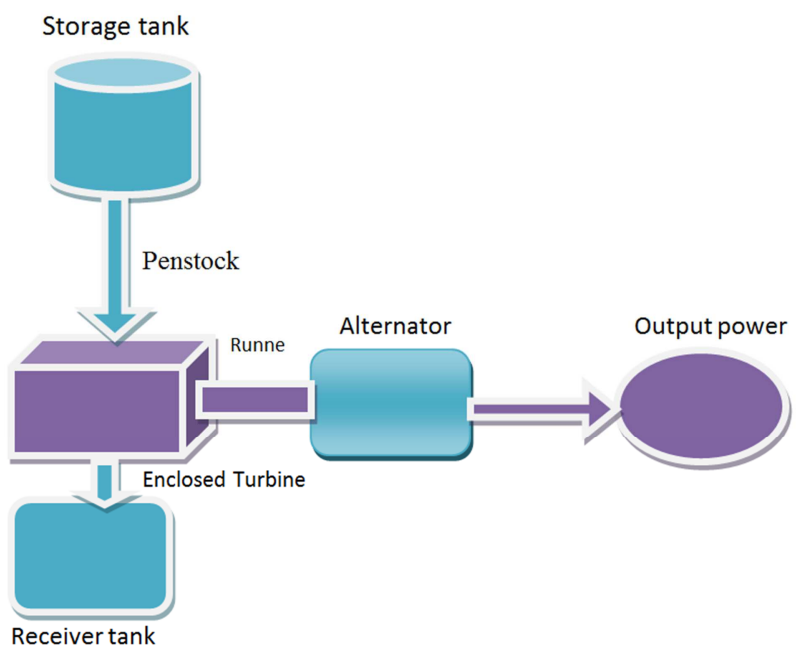

Figure 4. Block Representation of Mini Hydro Turbine Generator Model.

Generation of electricity from hydro power in small quantity for local or household consumption does not really require construction of dam. A mini hydro turbine generator could be effectively applied in an environment with little or abundance of water.

The mini hydro turbine generator is made up of a water storage tank (mounted at a particular height), penstock (PVC pipe), control valve, turbine system (self-fabricated) in an enclosed case, a pumping machine (for recycling of water) and a single phase alternator (self-constructed).

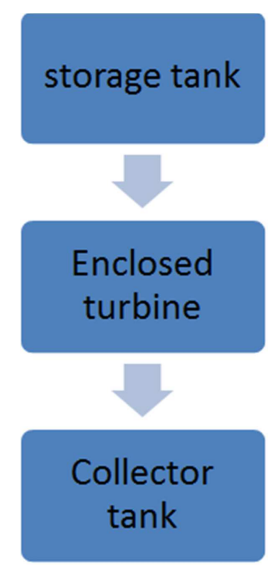

Figure 5. Water Flow Process of the System.

Initially, water will be stored in tank and it's conveyed by the penstock to the enclosed turbine where the power is being converted. After initiation of operation, the pumping machine start working by returning the water back to the storage tank and pumping directly to the enclosed turbine so as to increase the water pressure on the turbine blade, using the generated power to drive the motor, thereby making the system a close loop system.

\subsection{Implementation}

\section{Casing Implementation}

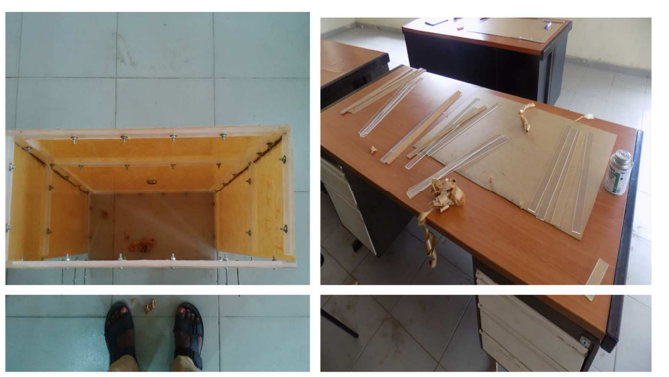

Figure 6. Construction of the turbine casing according to the designed dimensions.

The casing of the system is made of plastic material. Highlighted below are some of the excellent properties of plastic that supports our choice as the base material for the casing of this project. The choice of this material is to avoid corrosion which could result from the chemical reaction with the environment and other wear and tear that may take place in the process of power generation.

Furthermore, plastic is light weighted and dose not corrode it is convenience and easy during installation of the system as the casing did not add much weight to the system. Plastic exhibits high insulation properties thus reducing the risk of electric shock, chemical reaction with water which could lead to corrosion rapidly in the system after a period of time when the system is in operation.

\subsection{Pelton Turbine Fabrication}

The Pelton wheel is made of 9 inches metal-cutting disc, ten 45 degrees PVC elbow joints (1.5 inches diameter), ten 2 inches-long bolts (quarter inch diameter) and locking nuts.

Ten lines are drawn from the centre of the metal-cutting disc (angular distance of 36 degrees from each other) and on each line, a mark was placed at a distance of 2.3 centimetres from the tip of the disc. These marks are the points at which drilling will be carried out on the disc and also the points at which the turbine blades will be fixed to the disc. The marked-out points are then drilled with a 3.5 masonry drillbit, making out ten holes in the disc.

The ten PVC elbow joints make up the turbine cups. Each one has holes bored throughout at 2.3 centimetres from a particular chosen end. These holes are bored using a 3.5 drillbit and they are the points of slotting in the bolts and locking it to the disc holes drilled earlier mentioned.
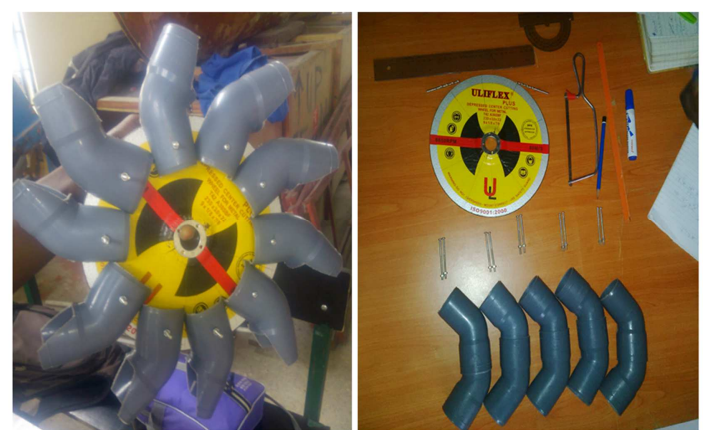

Figure 7. Some Materials Used for Turbine Component and the Constructed Turbine Blade. 


\subsection{Rotor Implementation}

The rotor was made up of 9-inches metal-cutting disc, rotor magnet template and ten Neodymium N50 magnets $(20 \mathrm{~mm} \times 10 \mathrm{~mm} \times 2 \mathrm{~mm})$.

The rotor template was made putting into consideration the number of poles required for the alternator and also the magnet measurement. Each sized magnet distances itself at 36 degrees.

The template was glued to the rotor disc which is made up of circular plastic, the magnets are positioned and glued in alternating poles (that is clock wise or anti-clock wise). The South Pole is positioned next to the North Pole in a repetitive sequence (till all the ten magnets were completely positioned).
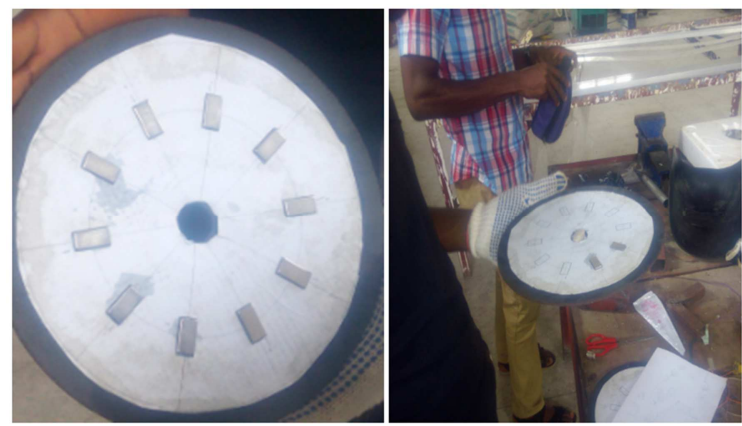

Figure 8. Construction of Rotor part of the Alternator.

\subsection{Stator Implementation}

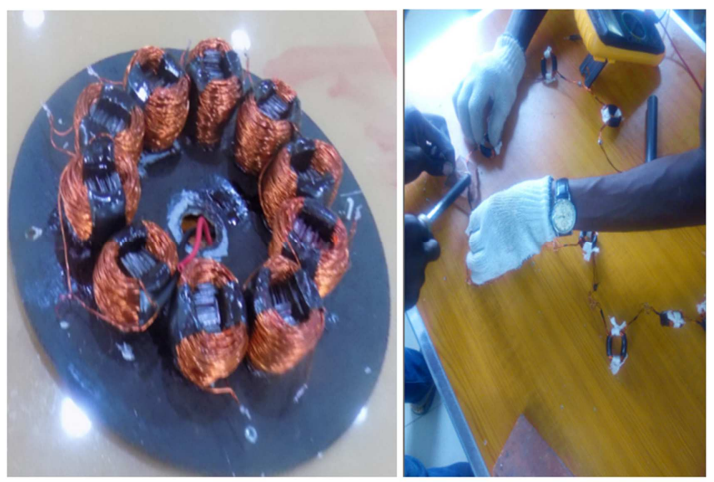

Figure 9. Terminated ten (10) Coils Stator Windings and soldering of its joints.

The stator is made up of ten 237-turns of standard wire gauge (SWG) 22 enamel-coated conducting coils, stator template, 9-inches metal-cutting disc, insulation tape, and glue.

The SWG 22 coil has a maximum ampere rating of 1.124A.

For the winding, a frame was made using the measurement of the magnet (length and breadth) and the coils were wound on the frame (the frame was wrapped with insulating tape to avoid short circuit of the coils and also prevent breaking of the coils insulation during the implementation of the construction work).

Individual windings were then connected to one another in an alternating manner; that is, the end of first winding is connected to the end of second winding, start of winding 2 to start of winding 3 , end of winding 3 to end of winding 4 , start of winding 4 to start of winding 5 , and so on till we get only the start of first winding as the main start and start of tenth winding as the main end.

\section{Implementation of Turbine System}
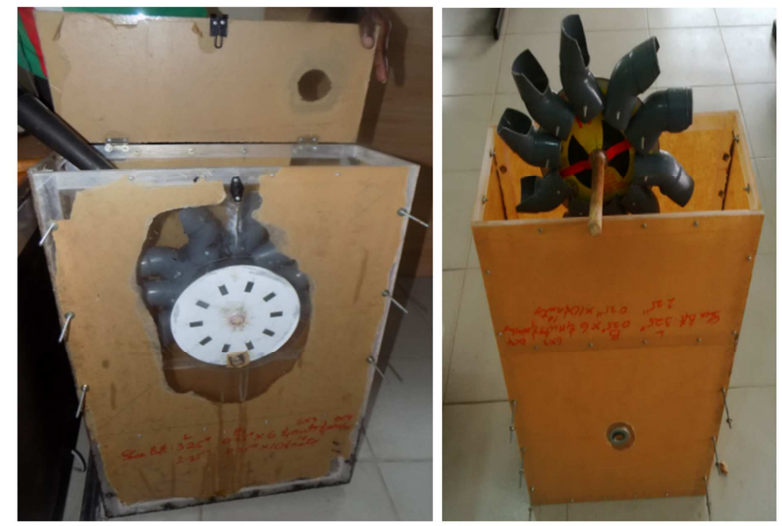

Figure 10. Constructed and Assembled Turbine System.

The turbine system as a whole was made up of transparent plastic casing, turbine, shaft and bearing. The bearings are attached to the two ends inside the casing where the shaft will be passing through. The bearing serves two major purposes, it serve as a support to the shaft and increases the efficiency of the turbine by limiting resistance during operation.

The top layer of the casing was constructed in a way that can be opened and closed fully with the use of hinges. The layer also has a water inlet of 1 inch diameter to allow recirculation of water. The bottom layer was completely sealed with an outlet point of 2 inch diameter pipe, connected to the outlet pipe was a jet nozzle to increase the pressure used in driving the rotor.

\section{Result and Discussion}

The result obtained was gotten from the various tests and analysis that were carried out on this research, the tests includes water flow rate test, stator coil resistance test, output voltage test and rotational speed test also analysis of power quality using oscilloscope to ascertain the wave form, also frequency test, voltage test and other preminary test needed during the process of quality control some of the results are shown on the table below.

Table 1. Flow Rate, Resistance and Rotational Test.

\begin{tabular}{lll}
\hline TEST & RESULTS & \\
\hline \multirow{3}{*}{ Flow Rate (Litre/Sec) } & Half flow & 1 \\
& Three quarter flow & 2.5 \\
& Full flow & 4 \\
\multirow{2}{*}{ Resistance (ohms) } & Single winding & 1.1 \\
& Total windings & 10.3 \\
& Minimum (Half flow) & 113.1 \\
Rotational speed (rpm) & Three quarter flow & 383.5 \\
& Maximum (Full flow) & 520 \\
\hline
\end{tabular}




\section{Conclusion}

From the research carried out on the mini hydro turbine model, using water which is economical, environmentally friendly, hydro turbine is also classified as part of renewable power generation system which will drive the economy and industrial revolution in countries where power generation is still very low. The construction and mass production of this hydro mini power plant will serve as alternative to power generation for domestic and small industrial consumption there by pulling such load off the national grid, which will then help the transmission company to redirect their power to heavy load centre in the country, thereby improving power quality, power security and reliability of power to the end users.

\section{References}

[1] Landis, Fred. "Waterpower." Microsoft ${ }^{\circledR}$ Encarta ${ }^{\circledR} 2009$ [DVD]. Redmond, WA: Microsoft Corporation, 2008.

[2] E. I. Okhueleigbe, A. O. Okhueleigbe, J. A. Ogbekhuilu, D. Okene, C. U. Ogu, A. O. Onyan "Revolution and Challenges Associated with Developing Countries Power Sector: A Case Study of the Nigeria Power System" Journal of Engineering Science Application (JESA), ISSN: 1115-9618, Page 80-92, Volume 9, Number 2, Published: September 2016.
[3] Arun Kurmar and Tormod Schei (2011). "special report on renewable energy sources and climate changes" (PP 442- 443) pdf.

[4] US Department of Energy, Efficiency and Renewable Energy (2003) "hydropower" pp 4-5.

[5] Karady, G. and Holbert, K. (2013). Electric Generating Stations, in Electrical Energy Conversion and Transport: An Interactive Computer-Based Approach, Second Edition, John Wiley \& Sons, Inc.

[6] E. I. Okhueleigbe (2016). Enhancing Power Distribution Network using Distributed Flexible Alternating Current Transmission System (D-FACTS) Devices, P.hD Thesis University of Benin, Benin City, Edo State, Nigeria.

[7] Secondary energy infobook (2015). "Hydro power generation". http://www.need.org accessed on 10:25am, $12^{\text {th }}$ of February, 2016.

[8] Energy Efficiency and Renewable Energy (2003).

[9] Hydropower "The Need Project" 2015

[10] Theraja B. L and Theraja B. K (2005). "Basic Electrical Engineering" vol 1, 7 pp 229. US Department of Energy, Efficiency and Renewable Energy (2003) "hydropower" pp 4-5. 